\title{
Pediatric community-acquired pneumonia in the ambulatory setting
}

\author{
Massimiliano Don • Francesca Valent
}

Received: 14 November 2009/Accepted: 19 November 2009/Published online: 9 December 2009

(C) Springer-Verlag 2009

\section{Dear Editor,}

Sir, we read with great interest the paper by CeveyMacherel et al. [1] focused on seeking the etiology of community-acquired pneumonia (CAP), defined by WHO criteria, in hospitalized children younger than 5 years of age and searching for clinical and laboratory markers for better focusing the therapy. By an extensive microbiological test panel, a potential etiological agent was found in $86 \%$ of the 99 prospectively enrolled patients. Apart from high serum nonspecific inflammatory markers, dehydration and pain were the only clinical signs/symptoms associated with bacterial pneumonia, although the second table shows that $59 \%$ of the patients with pain (13 of 22) suffered from mixed infections. The authors concluded their paper hoping for further studies that should include ambulatory children suffering from mild CAP in order to evaluate the correlation between clinical severity at admission and etiology in such specific group [1].

We have previously published our prospective results on etiology [2] and severity [3] of radiologically confirmed
CAP in 101 consecutive children treated in both ambulatory and hospital settings in all pediatric ages except newborns. The median age of the 74 outpatients ( 36 males) was 52 months. They were divided into the pneumococcal, atypical-bacterial, viral, and unknown etiology groups (15, 22,22 , and 15 cases, respectively) [2]. We did not find any significant difference (Kruskal-Wallis and Fisher's exact test) among the four groups as regards the body temperature on admission $(p=0.36)$, the percentages of patients presenting with vomit $(p=0.41)$, abdominal pain $(p=0.57)$, chest pain $(p=1.00)$, alveolar infiltration on chest X-ray $(p=$ $0.54)$, and the median values of C-reactive protein ( $p=$ $0.53)$, leukocytes $(p=0.41)$, and erythrocyte sedimentation rate $(p=0.23)$. In particular, median procalcitonin concentrations ranged from $0.50 \mathrm{ng} / \mathrm{ml}$ (unknown group) to $0.80 \mathrm{ng} / \mathrm{ml}$ (pneumococcal and atypical groups) in the four etiological groups $(p=0.77)$ [3].

With the present data, we think to have answered the above-mentioned author's question.

\section{References}

1. Cevey-Macherel M, Galetto-Lacour A, Gervaix A et al (2009) Etiology of community-acquired pneumonia in hospitalized children based on WHO clinical guidelines. Eur J Pediatr 168:14291436

2. Don M, Fasoli L, Paldanius M et al (2005) Etiology of communityacquired pneumonia: serologic results of a paediatric survey. Scand J Infect Dis 37:806-812

3. Don M, Valent F, Korppi M et al (2007) Efficacy of serum procalcitonin in evaluating severity of community-acquired pneumonia in childhood. Scand J Infect Dis 39:129-137 